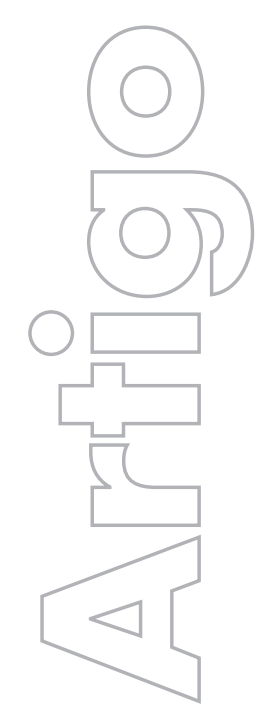

revista

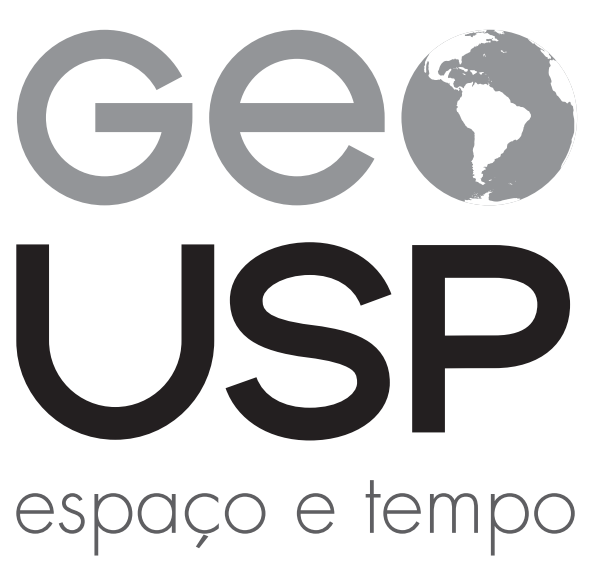

Volume $21 \cdot n^{\circ} 3$ (2017)

ISSN 2179-0892

\section{A natureza das crises nos} sistemas socioeconómicos capitalistas

\author{
Carlos Gonçalves \\ Centro de Estudos Geográficos \\ - Universidade de Lisboa
}

p. $755-770$

Como citar este artigo:

GONÇALVES, C. A natureza das crises nos sistemas socioeconómicos capitalistas. Geousp - Espaço e Tempo (Online), v. 21, n. 3, p. 755-770, dez. 2017. ISSN 2179-0892.

Disponível em: <http://www.revistas.usp.br/geousp/ article/view/110792 >. doi: 10.11606/issn.2179-0892. geousp.2017.110792.

\section{(c) $(1) \Theta$}

Este artigo está licenciado sob a Creative Commons Attribution 4.0 License. 


\title{
A natureza das crises nos sistemas socioeconómicos capitalistas
}

\begin{abstract}
Resumo
A atualidade é pautada por discursos contraditórios em torno da(s) crise(s). Este artigo faz uma incursão pelo quadro de conceitos que permitem compreender a crise, atendendo aos diferentes graus de intensidade e aos modos como se manifestam nos sistemas socioeconómicos. Cria-se assim substrato para refletir sobre as relações entre crise, capitalismo e neoliberalismo. Mantendo os paradigmas vigentes e ignorando a complexidade própria dos sistemas socioeconómicos, ampliam-se as condições para gerar e/ou fazer perpetuar, quadros de crise.
\end{abstract}

Palavras-chave: Crise. Colapso. Capitalismo. Neoliberalismo.

\section{The nature of crises in capitalist socio-economic systems}

\begin{abstract}
The present is controlled by contradictory discourses about the crisis. In this article we propose an overview on the conceptual framework that allow us to understand the crisis in socioeconomic systems. It creates conditions to think about the links between crisis, capitalism and neoliberalism. Protecting contemporary paradigms and ignoring the complexity of socio-economic systems, increases the conditions to generate and/or extend crisis.
\end{abstract}

Keywords: Crisis. Collapse. Capitalism. Neoliberalism.

\section{Introdução}

Crise serve de rótulo a parte dos acontecimentos contemporâneos. A crise é energética, climática, ambiental, económica, urbana, de valores, de legitimação, da democracia, da demografia, do estado social, das dívidas soberanas, do(s) capitalismo(s) etc.

$\bigcirc$ espetro de definições de crise é amplo e complexo. Essa estrutura de fronteiras indefinidas pode ser esbatida se colocada em perspetiva face a outros conceitos, tais como: distúrbio, revolução, colapso. Parte do "mundo ocidental" confronta-se com uma trajetória longa 
de crise (desde 2008) que remete a sua origem para a implosão da bolha imobiliária nos EUA, transpondo os seus efeitos para os países, regiões, famílias, mais vulneráveis. Neste contexto, importa considerar as origens e as derivas de consolidação nas sociedades capitalistas.

Num primeiro momento definem-se balizas para enquadrar o conceito de crise. De seguida, colocam-se em perspetiva as noções de crise, distúrbio e revolução e afloram-se fatores que conduziam sociedades robustas ao colapso. Por fim, discute-se a relação entre capitalismo e crise.

\section{A crise e as suas balizas conceptuais}

Antes de entrar na discussão do conceito, importa notar que a crise é uma construção social que bloqueia o progresso e faz perigar um modo de existência (Sugrue, 2005). Em última instância, sinaliza uma situação crítica em que as hipóteses de progresso se podem abrir ou eclipsar. No espetro de possibilidades que a crise fecha, e abre, consta o reposicionamento de trajetórias, o início de novos ciclos e a abertura para reavaliar modelos socioeconómicos.

Há que observar uma extensa plêiade de termos que remetem para causas, para consequências ou para múltiplas variações de misturas entre ambas. Previsibilidade, imprevisibilidade, obstáculo, problema, punição, oportunidade, ou ainda "mal necessário", são alguns dos rótulos utilizados. Ver a crise como um obstáculo inviabiliza as possibilidades de se perspetivar estes períodos como ocasiões para capitalizar aprendizagens, encarando-os apenas como barreiras a remover do caminho. Entender a crise a partir da dicotomia contrariedade vs oportunidade, segundo Mckendree (2011), abre caminho para a renovação que implica, aprendizagem, compromisso ético na comunicação (na representação) e considerar que, nas estratégias de desenvolvimento, a prospetiva prevalece sobre a retrospetiva. Por outro lado, associar a crise à ideia de "mal necessário", acolhe a bondade dos seus efeitos na "limpeza" de "vícios" que estorvam o bom funcionamento dos sistemas (Mckendree, 2011).

\section{Figura 1 - Efeitos de crises repentinas e prolongadas}

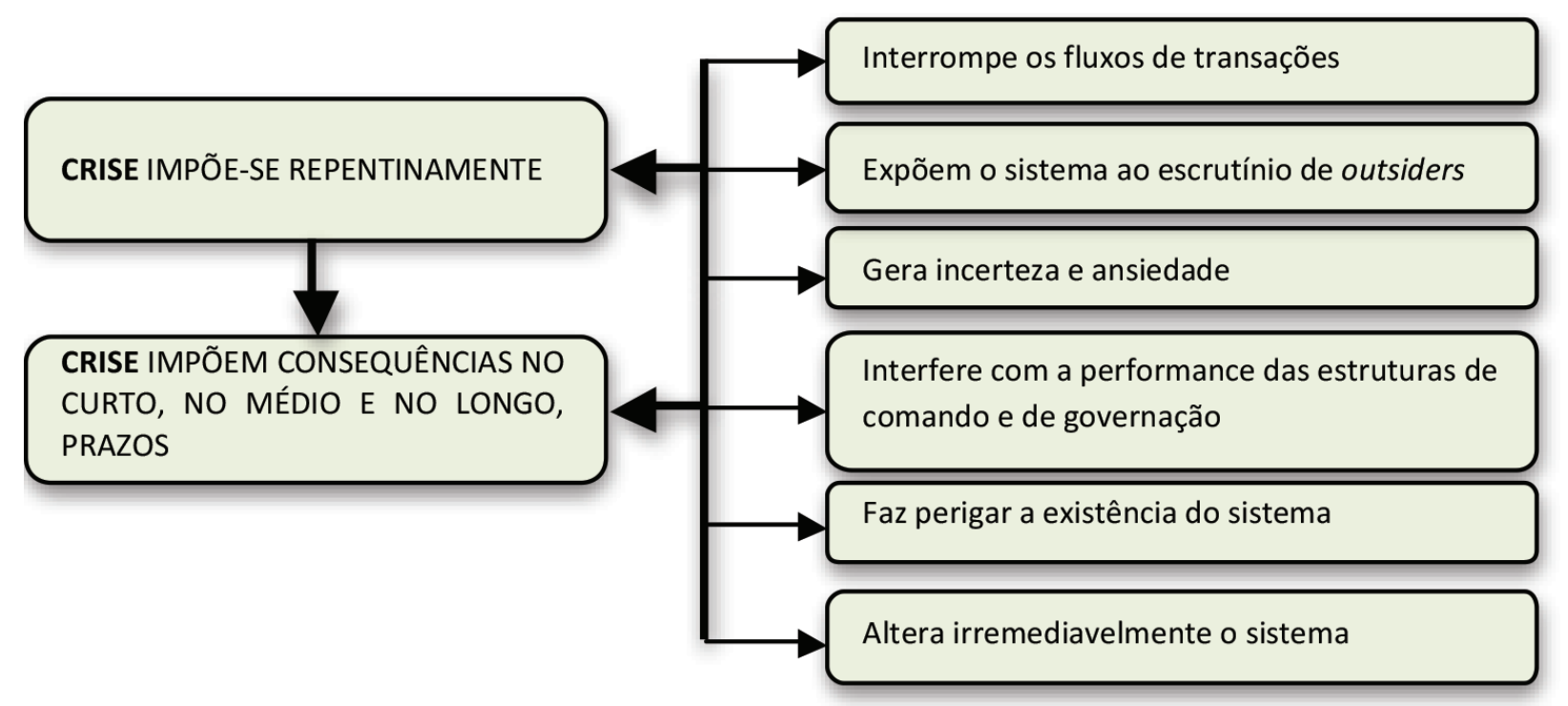

fonte: Adaptado de Mckendree (2011). 
Crise interrompe fluxos de transações, abala as estruturas de comando e de governação expondo-as a atores externos, acrescenta incerteza e ansiedade, compromete a existência do sistema vigente e, no final, altera irremediavelmente a sua configuração (Figura 1). A dilatação de cada um destes mecanismos é tanto maior, quanto mais repentina for a eclosão e distendida a duração.

Crise representa um evento não usual, de grande magnitude, com efeitos negativos que inflama riscos, provoca estragos e vulnerabiliza os sistemas, expondo-os a perdas. Produz consequências factuais, mas também interfere nos cenários percecionados, porquanto há uma componente das crises que desgasta a esperança. A incerteza conduz a antecipações de eventos negativos e faz desabar o edifício de expectativas que os atores, envolvidos no desenvolvimento dos territórios, constroem paulatinamente. Este estádio de expectativa, antecipatória de algo negativo, propagando-se numa comunidade, bloqueia-lhe a trajetória de progresso (Mckendree, 2011).

Formular a multiplicidade de enfoques e circunscrever as dimensões envolvidas na gestão de crises, são propósitos exigentes. É necessário conjugar a dimensão do risco a gestão das respostas e a coordenação da comunicação. Antever o risco pressupõe um cálculo de vulnerabilidade que, por exemplo, tendo em mente a ótica da proteção civil, reproduz a existência de um determinado nível de predisposição para o desastre. Gerir a crise desloca a atenção para o antes, o durante e o depois do fenómeno que lhe dá início, remetendo, para avaliações do tipo, "ex-ante"," on-going" e "ex-post". Considerar a resposta à crise, por sua vez, clama por instrumentos de contenção que evitem o alastramento, impondo-lhe um limite. Coordenar a comunicação, alinha-se também com a prerrogativa da contenção, porém, trabalha-a a partir dos conteúdos e dos modos mais adequados de fazer chegar informação aos diferentes atores (Mckendree, 2011).

Um cambiante diferente, sobre a crise, é proposto pela leitura cíclica que recorrentemente se produz acerca do progresso das sociedades. Observada a partir da variação de recursos disponíveis (por via da sua gestão e acumulação), da capacidade de produção (fruto dos avanços tecnológicos e dos processos de organização do trabalho) ou da dinâmica de procura (acionada, ou retraída, pelos mecanismos de transferência de capital do ciclo de produção para as famílias), a crise aparece como fase lunar dum processo evolutivo. Várias são as explicações para o surgimento dessas formas de retenção, inversão ou, no extremo, colapso de um qualquer projeto de sociedade. Todavia, a primeira formulação para o que se convenciona chamar, nos dias de hoje, crise sistémica, crise económica ou crise social, de acordo com Habermas (1979), nos é oferecida por Karl Heinrich Marx (1818-1883). Pioneiro nesse tipo de interpretação, Marx define crise como um estado de degradação da capacidade para resolver os problemas ameaçadores da existência de um dado sistema. Quer isto dizer que, em situações de crise, o sistema social revela-se incapaz de formular soluções. No extremo, esta situação pode conduzir à desintegração.

A eclosão de crises nos sistemas sociais, não pode ser vista como ocorrência, mais ou menos, acidental. Pelo contrário, estas circunstâncias serão melhor entendidas como efeitos estruturais intrínsecos aos sistemas que, em determinada conjuntura, inviabilizam a sua integração hierárquica. Deste modo, desmantelam-se os circuitos de complexidade organizada e 
comprometem-se os mecanismos que asseguram identidade e existência (Habermas, 1979). Decorrente desta prerrogativa, é necessário considerar a viabilidade de se poder apartar, num sistema urbano, aqueles que serão os elementos centrais, dos periféricos (ou acessórios). Dizer que os primeiros são os que garantem a sua identidade, ajuda, mas não resolve a questão. Importará, de seguida, definir os limiares a partir dos quais se considera que se mantém, ou se perde, a identidade. No caso dum organismo específico, o problema é de fácil resolução, na medida em que este terá, associadas à sua existência, fronteiras espaciais e temporais, "ótimas". Porquanto, essas extremas são traduzíveis para valores empíricos, além dos quais o organismo $x$ ou y não sobrevive.

Retirando consistência a muitas das análises produzidas, a linearidade assinalada no parágrafo anterior, assenta bem num organismo isolado, mas não é verificável nos sistemas complexos, como o são as estruturas de organização de fluxos próprias dos sistemas socioeconómicos. Linearidade é uma característica das linhas retas que, por definição, não têm desvios, são "bem-comportadas". Na sua contracapa, a não linearidade anda mais próxima do imprevisto, dos comportamentos inexatos que, na verdade são praticamente associados a quase todos os sistemas. Não obstante este facto, quase toda a ciência atual assenta em raciocínios lógicos lineares, a partir dos quais o mundo "naturalmente" se organiza. Morgado e Rocha, (2006, p. 4), desmantelam este racional da seguinte forma:

[...] uma bola chutada com o dobro da força adquire o dobro da velocidade, ou um buraco com o dobro do tamanho leva o dobro da água. Se isto não fosse verdade então como seria possível prever alguma coisa? Para surpresa de muitos o estado natural do mundo é não linear, a linearidade é apenas uma aproximação.

Nos sistemas complexos, as combinações possíveis de modos de funcionamento são múltiplas, compondo uma emaranhada teia de relações que por sua vez interferem, quer com o posicionamento dos valores "ótimos" de funcionamento, quer com os limiares a partir dos quais se alteram, irreversivelmente, os mecanismos de controlo. Casos em que os limiares são ultrapassados implicam a reconfiguração da matriz identitária do sistema urbano. Guinam para aqui as noções de auto-organização, não linearidade, interação ordem/caos e propriedades emergentes (Morgado; Rocha, 2006).

Modificações profundas tanto podem ser vistas como processos de aprendizagem, como podem ser entendidas como estádios de dissolução condizentes ao colapso do sistema (Habermas, 1979). Resolvida a crise, por uma ou por outra via (aprendizagem traduzida em adaptação ou dissolução convertida em colapso), manter-se-á a interrogação: assistimos ao surgimento de um novo sistema, ou consumou-se a regeneração do sistema precedente? Uma vez que nem todas as mudanças serão detonadas por uma crise, a questão remete, para que se discuta, e se relativize, o conceito de crise.

\section{Crise, distúrbio, revolução}

Habermas (1979) dá um contributo relevante nesta matéria, quando estabelece a diferença entre crise e distúrbio. Concordando com o autor, podemos considerar que estamos perante uma crise quando os membros de uma sociedade experienciam alterações estruturais, de tal 
modo profundas que se desencadeia a perceção de que tanto a existência como a identidade social estão em jogo. Ou seja, a crise traduz-se na desintegração das instituições sociais. Por seu lado, um distúrbio assinala um impasse, ou uma fase de indefinição no processo de integração social. Dito de modo diferente, quando os fundamentos basilares das estruturas normativas estão na eminência da rotura, a sociedade confronta-se com um distúrbio (Habermas, 1979, p. 3).

$\bigcirc$ esforço de destrinça dos conceitos que estabelecem relações de vizinhança com a ideia de crise ganha em se considerar o contributo que os historiadores podem dar. Nesse campo do conhecimento é comum proceder-se à clarificação do que são simples alterações estruturais, revoluções e colapsos desencadeados em impérios, Estados ou outra qualquer entidade representativa de uma sociedade ou comunidade. Revolução americana, revolução francesa, revolução industrial ou revolução dos cravos, são alguns dos marcos históricos que assumiram a força da designação por forma a com ela se assinalar uma mudança profunda, culminado numa transfiguração completa de um código de valores que geria a sociedade.

$\bigcirc$ confronto direto (inevitável) com um novo início é próprio dos eventos que a história convencionou designar por revolução. Claro está que uma revolução decorre de uma crise profunda. Isto é, pouco tem que ver com uma mera mudança de circunstâncias incapaz de alterar o curso da história que não reclama um recomeço, remete apenas para uma fase diferente do ciclo [...] (Arendt, 1963, p. 21). Todavia, não se poderá enjeitar outro tipo de revoluções que sendo mais sorrateiras, nada de discreto têm nos efeitos que provocam.

A este propósito, Orlando Ribeiro (1945), clarificando as razões da dispersão do povoamento português, não deixa passar despercebida uma dessas transformações: disfarçadas, mas revolucionárias. Chama-lhe a "revolução do milho", advogando que desde a conquista romana, nenhuma outra alteração produziu efeitos tão profundos como os que resultaram da introdução desta cultura no território nacional. E enumera:

[...] grandes arroteias, suspensão dos pousios, aumento da área regada pela construção de socalcos, agricultura intensiva, variada e minuciosa, declínio do pastoreio por falta de espaços abertos à deambulação dos rebanhos, separação definitiva do campo e do bosque, maior iniciativa no trabalho familiar, decadência irreversível do espírito de comunidade, individualismo que se traduz no parcelamento da terra, na multiplicação de sebes, muros e divisórias e na disseminação de habitações.

Conclui: "tudo o milho favoreceu, permitiu ou provocou" (Ribeiro, 1945, p. 122). É este o caso duma variável de progressão lenta que transforma amplamente a estrutura do sistema, por oposição à ação das variáveis de difusão rápida, próprias e recorrentes, nos sistemas dinâmicos. Não raras vezes se defende que, a ação das primeiras (as graduais) é mais impactante, produzindo transformações que inviabilizam, definitivamente, o retorno do sistema ao ponto de partida, marcando uma instabilidade irreversível que produzirá, a jusante, outra matriz na paisagem (Carpenter et al., 2001).

A componente social encontra relação com a ideia de revolução apenas na modernidade, quando se coloca em causa o facto, até então aceite como "natural", de que a pobreza é parte integrante da condição humana. Esse preceito é substituído pela convicção de que "a 
vida na terra pode ser abençoada pela abundância em vez de ser amaldiçoada pela escassez" (Arendt, 1963, p. 21). Tal modificação na conceção face ao modo de conceber a condição humana "was prerevolutionary and American in origin" (Arendt, 1963, p. 21). $\bigcirc$ ponto de rutura, assinalado pela autora, ocorre quando se abandona, irreversivelmente, a matiz que interpreta o mundo a partir da "natural" separação, que até então se fazia, entre ricos e pobres.

Seguindo a argumentação de Arendt (1963), o efeito revolucionário dessa transformação é o elemento precursor que viabiliza a revolução francesa. Essa perspetiva sugere que o sistema social alienou sua identidade quando, no decurso de um salto geracional, os que herdam, deixam de se reconhecer no quadro de convenções dos que herdaram. Tomada como definição de crise, essa conceção obriga a partir em busca do que poderá ser o desligamento face a uma configuração de identidade social. Uma crise de identidade social manifesta-se quando se avolumam problemas de liderança ou, dito de outro modo, de sustentação das representações.

Haverá um ponto em que a profundidade das roturas sociais e de representação inviabilizam a atuação dos mecanismos de estabilização nos sistemas socioeconómicos? Esta questão conduz-nos à discussão que coloca em perspetiva os conceitos de crise e de colapso.

\section{Crise e colapso}

Porventura teremos de adotar uma linguagem mais contundente para entender os processos que conduzem ao colapso. Primeiramente admitamos que a história tem ritmo, articulado (ou não), com marcações de cadência. Ciclos de crescimento, expansão e dissolução ou mudança, resposta e suicídio são hipóteses que concorrem para um mesmo entendimento do colapso como fim de um percurso marcado por fases de natureza distinta.

Numa "fotografia escrita", Orlando Ribeiro (1945), referindo-se às transformações estruturais nas regiões mediterrâneas assinala que a instabilidade social se transfere diretamente para o povoamento. $\bigcirc$ autor descreve:

[...] as casas aglomeram-se, apinham-se em lugares altos e fáceis de defender. Nestas lutas obscuras (dos agricultores que se defenderem de salteadores e das povoações costeiras que lutam contra as "infestações" de piratas), agora extintas para logo desaparecerem, estará a explicação de muitas regressões da história mediterrânea (Ribeiro, 1945, p. 22).

Numa outra escala, indo de encontro à observação das grandes regressões e mesmo dos mais espetaculares colapsos Ferguson (2010) fala-nos da vida e, sobretudo, da morte dos impérios. Recorre aos dizeres do filósofo britânico Henry St. John (1678-1751) para nos dizer que estes poderosos centros carregavam com eles a fórmula da destruição. Crescem e desenvolvem-se com o tempo, todavia, tarde ou cedo, confluem para um caminho que os conduz à dissolução. Nas palavras deste filósofo, cada hora vivida pelos grandes centros de agregação de poder, será menos uma que terão para viver.

Estas estruturas de poder estabelecem mais pontes de comparação com um monte de térmitas do que com as pirâmides do Egito. Resultam de uma tensão entre ordem e desordem numa espécie de caos controlado. Parecendo que estão em perfeito equilibrio, na verdade, estão em adaptação constante. Tomados como estruturas complexas, organizações da dimensão 
daquelas a que nos temos referido, no decurso da sua história, são confrontados com fases críticas, nas quais uma pequena perturbação desloca o sistema do plano equilibrado para uma crise, após a qual, qualquer ligeira perturbação será suficiente para o fazer colapsar (Ferguson, 2010). Assim, o colapso corresponderá a um fim de ciclo. $\bigcirc$ mesmo será dizer que se trata duma situação para a qual, uma sociedade em crise, não encontrou saída.

Colapso configura uma drástica contração na dimensão de uma população e/ou uma considerável anulação da complexidade política, económica, social numa área e por um período de tempo consideráveis. $\bigcirc$ colapso surge como corolário num acumulado de eventos de declínio. Um fenômeno de colapso define-se por:

[...] an extreme form of several milder types of decline, and it becomes arbitrary to decide how drastic the decline of a society must be before it qualifies to be labeled as a collapse. Some of those milder types of decline include the normal minor rises and falls of fortune, and minor political/economic/social restructurings, of any individual society; one society's conquest by a close neighbor, or its decline linked to the neighbor's rise, without change in the total population size or complexity of the whole region; and the replacement or overthrow of one governing elite by another (Diamond, 2005, p. 12).

A falta de progresso é insuficiente para fixar o conceito de crise. Porventura colocá-la no plano do impasse (uma espécie de purgatório) entre uma sequência de pequenas (ou grandes) mudanças que vulnerabilizaram o sistema social e o colapso do mesmo, será mais adequado. Uma crise reproduz "condições crônicas de atividade subnormal durante um tempo considerável sem qualquer tendência marcada para recuperação ou para o colapso total" (Krugman 2012, p. 12).

Paul Krugman sugere que saber o que provoca os ataques cardíacos não é o mesmo que ter a solução para os tratar. Levanta-se aqui o véu para a necessidade de se perceber os mecanismos que conduzem à crise e aí chegados, destrinçar as soluções que "apenas" evitam o colapso das que permitem reverter as ditas "condições crônicas de atividade subnormal" (Krugman 2012, p. 12).

\section{Interruptores de crises}

Civilizações de grande relevo estão armazenadas na história, colocadas lá, não só pela grandeza da sua implantação, mas também pelos enigmas em que se enredam as explicações do seu colapso. $\bigcirc$ colapso da civilização Maia, dos impérios Romano ou Viking são exemplos disto. No caso na civilização Maia, são de variada ordem as evidências das suas evoluídas competências nas técnicas arquitetônicas, nas soluções urbanísticas, nas sofisticadas manifestações artísticas ou no inovador (à época) código de comunicação escrita. De que modo estrutura socioeconómicas, tidas como inovadoras e robustas, colapsaram?

Diga-se que muitos dos ingredientes comummente associados a sociedades vulneráveis à extinção não se aplicariam à realidade Maia. Dimensão reduzida, isolamento geográfico, implantação em ambientes singulares e desajustes culturais e tecnológicos face aos padrões do seu tempo, não são predicados atribuíveis à civilização presente nas cidades maias. Decorre 
daqui que os colapsos não são apenas próprios de sociedades periféricas implantadas em áreas vulneráveis. $\bigcirc$ exemplo que aqui evocamos nos leva a concluir que os fenômenos de colapso podem também suceder em contextos de sociedades avançadas e criativas (Diamond, 2005, p. 168). A conclusão retirada pelo autor, contradizendo Ferguson (2010), não vaticina uma leitura fatalista do género: a tendência de todas as sociedades é o colapso. Todavia, defende-se que até mesmo a sociedade mais rica e/ou de vanguarda no domínio tecnológico, pode ser confrontada com problemas sociais, ambientais, económicos. Esses problemas, quando subestimados (porque mal interpretados ou porque atacados com soluções desajustadas), podem fazer perigar a existência de sociedades, aparentemente robustas.

Tendo o ambiente como linha de observação, Diamond (2005) procura responder a interrogações intemporais, tais como: porque algumas sociedades colapsaram e outras não? o que torna certas sociedades especialmente vulneráveis? que processos conduziram as sociedades que colapsaram a cometerem, o que designa por "ecocídio"? como justificar o facto de algumas sociedades se recusarem a ver os riscos a que se auto submetem? que soluções tiveram sucesso no passado?

Certo é que não existe (nunca existe) termo de comparação entre as condições do passado e as do presente. Note-se que as diferenças se materializam na mitigação da exposição a vulnerabilidades por via do poder que a tecnologia disponibiliza ao homem do séc. XXI. Tal decorre da crescente integração dos sistemas físicos e sociais no que se convencionou chamar globalização, bem assim, fruto do alargamento das respostas que a medicina moderna apresenta diariamente, a que se soma, a consolidação do conhecimento acerca das sociedades que a história assinala como referências.

No contraponto, também é de assinalar que a sociedade atual confronta vulnerabilidades, que as do passado nem sequer conseguiriam perspetivar. Podem ser apontados como exemplos, o potencial destruidor da tecnologia, o efeito globalizante que decorre do contágio que um pequeno colapso na Somália (ou noutro qualquer ponto do planeta) pode provocar nos EUA ou na Europa (a globalização inviabiliza a possibilidade de se isolar episódios de colapso num pequeno território), a dependência que grande parte da população do planeta apresenta face a um número reduzido de substâncias farmacológicas e o simples facto de termos uma massa humana substancialmente maior, e a crescer, sobre a superfície terrestre (Diamond, 2005).

Atuações predatórias sobre o ambiente, variações climáticas (locais ou globais), relações conflituosas entre comunidades ou sociedades, enfraquecimento de relações e de contacto cultural e comercial com civilizações aliadas, ou o enfraquecimento em si mesmo das regiões com as quais se estabelecem parcerias proveitosas (um reforçando a coesão social e outro suprimindo lacunas no acesso a bens essenciais), são alguns dos fatores apontados como responsáveis pelo colapso de sociedades no passado (Diamond, 2005).

$\bigcirc$ facto de regiões diferentes darem respostas iguais a problemas semelhantes é mais um fator a acrescentar aos anteriormente apresentados. A resposta que uma sociedade configura (ou que está habilitada a configurar) não pode ser apartada do seu contexto político, económico, social ou institucional. Tão pouco pode ser deixando de lado o código de valores culturais que a regem, a começar pelos que moldam as relações de produção e matriz de trocas dos sistemas socioeconómicos. Vejamos o que sucede no amplo espaço de implantação, e de mutação, do capitalismo. 


\section{Crise e capitalismo}

Resolvidas as tensões que marcaram o longo período da Guerra Fria, inicia-se uma fase de transformações globais profundas: a União das Repúblicas Socialistas Soviéticas (URSS) desintegra-se, o bloco socialista na Europa do leste fragmenta-se, os regimes comunistas nos vários cantos do mundo desmembram-se e, inicia-se um processo de restabelecimento gradual do capitalismo em vários países (China e Vietname são apenas dois exemplos).

Com efeitos traduzíveis para a escala global, todas estas mudanças reenquadram as estruturas políticas, económicas e sociais, incorporando, em graus diferenciados, a rejeição da proposta marxista sobre a qual se tinham congeminado sociedades socialistas (Li; Hersh, 2002). O corolário do entusiasmo que a viragem do mundo para uma nova fórmula socioeconómica produz, sintetiza-se na ideia de que o socialismo passaria a ser considerado um resíduo na narrativa histórica.

Com o processo de "descongelamento" definitivo da Guerra Fria, não foi apenas um modelo social que se extinguiu e também não foi uma mera transição para um período pós-Guerra. O que então se propunha era o encerramento dum capítulo da história construído na confrontação dos modelos socialista e capitalista. A democracia liberal ocidental universaliza-se como forma acabada de governação (Fukuyama, 1989; 1992). Numa interpretação diferente, sugerida por Li e Hersh (2002), é atribuído a Fukuyama o anúncio do capitalismo como derradeiro patamar da evolução das sociedades.

$\bigcirc$ capitalismo como modelo social, bem assim, a perspetiva que o entende como um estádio civilizacional avançado, é confrontado com crescentes frentes de contestação que vão definindo os contornos da conceção dita neoliberal. $\bigcirc$ neoliberalismo é visto como uma fusão dos fundamentos da economia neoclássica (o mercado ao comando em vez do Estado), onde o lucro é o fermento do crescimento económico, o moralismo (assente em estruturas como a família) é elevado ao estatuto de autoridade e os princípios do comércio internacional livre derrubam as barreiras setorial ou territoriais protecionistas (Moody, $1997^{1}$ apud Brenner; Theodore, 2002).

Do puzzle que resulta desta formulação, emerge o paradoxo: é necessário um Estado com capacidade de intervenção (de mão visível) para que o mercado possa impor a "utopia" de se libertar de todos os constrangimentos que o mesmo Estado the possa impor. Este paradoxo abre caminho para outro, que resulta, desta feita, da sua plena aplicação. Quando aplicadas as políticas determinadas pelos atores que dirigem os mercados (liberalizados), ao invés de se repartir equitativamente os investimentos e os recursos, emergem as "falhas de mercado", desenham-se estruturas de polarização social e amplificam-se as desigualdades de desenvolvimento territorial a várias escalas. Como corolário, se se concordar com Gill (1995, p. 407), chamado à coação por Brenner e Theodore (2002) quando catapultadas para um regime de funcionamento neoliberal, as políticas públicas tendem a submeter a maioria (relativizando os princípios democráticos) às leis do mercado (escritas e regidas por uma minoria).

O paradoxo, neste caso, está no facto de isto acontecer ao mesmo tempo que se capturam os instrumentos de proteção social, patrocinados por recursos públicos, pelos mais fortes, eles próprios atores por excelência do mercado livre (Brenner; Theodore, 2002). Os autores

1 MOODY, K. Workers in a Lean World. New York: Verso, 1997. 
recorrem a Amin (1997), Bourdieu (1998), Gill (1995), Isin (1998), Jessop e Stones (1992), Peck e Tickell (1994), para solidificar a ideia de que os desajustamentos entre a tese de que os mercados se autorregulam e os seus resultados práticos são de monta. Afirma que estes e outros autores demonstram que, os episódios de estagnação repetem-se, as desigualdades multiplicam-se e a competição territorial inflama os vários tipos de insegurança. Diz ainda que esses efeitos são tanto mais agudos quanto maior a aplicação das doutrinas neoliberais.

Não se contradita a contundência da tese de Fulkuyama, assente no vaticínio de que o liberalismo (com ou sem "neo") "will govern the material world in the long run" (Fukuyama, 1989, p. 1), na medida em que o que interessa aqui é perceber o modo como as estruturas do capitalismo global (Silvey, 2010), como sistema dominante, lidam com a crise. De natureza complexa e sistémica, o capitalista convive com distúrbios (quer de cariz externo quer de origem interna), provoca e, na maior parte dos casos, assimila choques. Todavia, por vezes, ruturas pontuais degeneram em crises generalizadas.

A crise, não raras vezes, é vista como uma componente inevitável do capitalismo, como sistema dominante baseado no mecanismo: dinheiro serve para gerar mais dinheiro. É o lucro, não são as necessidades sociais, quem comanda a produção. É esse o quadro em que a crise é recorrente, oscilando entre ciclos expansivos e outros de contração nos quais se destrói, ou se desperdiça, boa parte do valor criado em fases prévias.

Os sistemas de produção das sociedades são certamente complexos, assentes em estruturas sociais com interdependências variadas pelo que a sua reprodução convoca relações multidirecionais entre diferentes atividades produtivas. Todavia, essas atividades envolvem um número restrito de capitalistas com estratégias individuais orientadas para o lucro. Esta é uma peculiaridade basilar do capitalismo de que nos dá conta Shaikh (1978) e que deve sustentar as análises ao processo de desenvolvimento de comunidades, cidades ou regiões.

A crise é entendida como efeito generalizado do fracasso das relações económicas e políticas que o sistema gera com o seu próprio funcionamento, este, centrado na reprodução do capital (Shaikh, 1978). São endémicas, correspondem a fases de destruição de recursos, resultam de interrupções no processo de acumulação e surgem ciclicamente na medida em que o tal processo de acumulação envolve períodos de desvalorização de algumas componentes do investimento, colocando em causa a integração social (Habermas, 1979).

Enquanto expressão do processo social, a competição expropria, de modo seletivo, capitalistas individuais e subtrai aos trabalhadores o emprego que configura o seu meio de subsistência. De acordo com Habermas (1979) daqui resulta a transfiguração da crise económica inicial, na crise social consequente, colocando a descoberto (no meio de ambas) as tensões entre grupos sociais. Este é um domínio escondido da economia de mercado evidenciando o quanto é falaciosa a pretensão de entender o mercado livre como entidade desprovida de poder.

É este o quadro que conduz a que, no seio das sociedades capitalistas, se interprete a crise de modo ambivalente. As explicações para tal balançam entre o posicionamento do foco nos desequilibrios provocados pela reprodução do investimento, gerados dos centros de controlo, na importância dada às contradições impostas pelo capitalismo, às relações sociais e à destabilização que decorre de variados tipos de contingências, que podem ir da descoberta de uma nova provisão de recursos naturais até à falência de uma empresa particular (Tabb, 2010). 
Procurar explicar a presença recorrente de crises nas sociedades capitalistas contrapondo, por uma via, os efeitos do subconsumo e, por outra, a queda dos lucros decorrentes da sobreprodução é mais um dos caminhos que desembocam numa bifurcação. Esta dualidade, por definição, coloca em confronto duas fações. Apesar de ambas assentarem no entendimento de que as relações entre economia e sociedade estabelecem uma rede de vasos comunicantes (tudo afeta todos e cada um afeta tudo e todos), a construção argumentativa desenha-se em duas frentes distintas: uma linha advoga que as crises se previnem com o aumento da procura, isto é, se os consumidores gastam mais, mais pode ser vendido, logo mais pode ser produzido e mais pode ser transferido para as famílias (por via dos salários ou mediante arranjos redistributivos viabilizados pelos impostos gerados nos vários pontos da cadeia). Assim, veremos a redução do consumo como uma causa da crise. A segunda linha argumentativa, contrapõem-se à primeira, porquanto, é o aumento do poder de compra (alimentado na calibração mais favorável da repartição do valor gerado entre o trabalho e o capital), que provoca falhas no sistema e, por conseguinte, é daqui que emergem as crises. É o sobreaquecimento da economia, provocado por vagas de consumismo custeado por salários mais elevados, por crédito barato e acessível (ou acessível porque barato) ou pela conjugação de ambos que está no centro da explicação para as crises. Este processo foi catalogado como estagflação. $\bigcirc$ termo foi, pela primeira vez, usado para emoldurar a queda na produção de riqueza conjugada com o aumento do desemprego e dos preços, que marcou o período de crise entre 1973 e 1975 (Tabb, 2010). A estagflação é um processo de eclosão de crises contrário à abordagem Keynesiana, pelo que assenta a explicação na retração do consumo (Clarke, 1993).

Competitividade, desregulação dos mercados e supressão da intervenção do Estado nos vários campos de desenvolvimento das sociedades, representa o fulcro da ideologia neoliberal que vislumbra, por este espetro, a forma ótima do desenvolvimento económico (Brenner; Theodore, 2002). Entendida por alguns como "utopia of unlimited exploitation" (Bourdieu, $1998^{2}$ apud Brenner; Theodore, 2002, p. 350), a matriz dita neoliberal de posicionamento estratégico que visa reorientar as estruturas socioeconómicas define-se, com mais clareza, a partir do pensamento de Friedrich Hayek (1899-1992) e de Milton Friedman (1912-2006). O combustível que acelerou a sua adoção gradual foi a receção global que teve lugar no decurso da década de 1970 e início da seguinte. Prevaleceu a interpretação de que estavam esgotados, tanto o modelo de produção industrial fordista como o que desenhava o Estado social de inspiração Keynesiana em "vigor" desde o pós-Guerra. Inglaterra, com Margaret Thatcher (1925-2013) e os EUA, com Ronald Reagan (1911-2004) colocaram-se na dianteira da aplicação prática de tais princípios de (re)organização social, acompanhados de perto (com matizes mais moderadas), por países como o Canadá, Nova Zelândia, Alemanha, França, Itália e mesmo pela Suécia (Brenner; Theodore, 2002).

Da frente estabelecida pela soma do "Thatcherismo" e do "Reaganismo" e pelo contágio a países como os que se apontou, sobe-se para um patamar em que se começou a definir uma arquitetura global para esses princípios. Os EUA, primeiro isoladamente, e depois, no âmbito do então G-7, introduzem a ponte para que este modelo pudesse ser implementado em países periféricos ou semiperiféricos que também enfrentavam os impactos da crise global.

2 BOURDIEU, Pierre. Acts of Resistance: Against the Tyranny of the Market. New York: Free Press, 1998. 
A ideologia do capitalismo neoliberal globalizou-se pela ação das instituições que se tinham criado em torno dos acordos de Bretton Woods (assinados em 1944), onde se discutiu uma estrutura económico-financeira global, assente nos pilares definidos por John Maynard Keynes (1883-1946). Um desses pilares consistia na criação de um Banco Mundial que regulasse a liquidez do sistema financeiro global (Foley, 2009). A jusante, somam-se as ações do Banco Mundial e do Fundo Monetário Internacional de desenho e implementação de programas de "ajustamento" estrutural (de austeridade), distendendo esta matriz de organização socioeconómica à escala global (começando com intervenções em países em desenvolvimento). $\bigcirc$ desvio que a estratégia neoliberal impõe ao capitalismo, permite que as relações que o sustentam sejam "the dominant political and ideological form of capitalist globalization" (Brenner; Theodore, 2002, p. 350).

Vista no quadro de funcionamento das sociedades capitalistas, a definição de crise internaliza falhas generalizadas de reprodução do capital, associadas a distúrbios nas relações económicas e políticas (Shaikh, 1978). A exposição a perturbações generalizadas, de ordem intrínseca ou extrínseca, é uma contingência própria da natureza da produção capitalista. A questão coloca-se sempre em saber qual a magnitude do choque que destabiliza, bloqueia, ou faz colapsar, o sistema. Em configurações robustas (em que as vulnerabilidades são inexistentes ou estão resolvidas), as situações desestabilizadoras são facilmente reversíveis. Já em sistemas enfraquecidos, qualquer pequena adversidade é suficiente para despoletar os mecanismos que o conduzem ao colapso (Shaikh, 1978).

Poder-se-á dizer que a crise, pelo prisma do funcionamento dos sistemas de reprodução capitalista, assume duas faces: numa, a crise é vista sob um filtro de "lei da natureza" - por aqui, decalcam-se os contornos da tradição laissez-faire que muito bebe na ideia de que a natureza humana entronca nas leis que gerem a natureza física/biológica; na outra face, vislumbra-se a crítica à primeira - isto é, à lógica de que a oferta determina a sua própria procura, contrapõe-se outra, dizendo que a procura pode ser delineada mediante investimentos devidamente planeados, sendo este o determinante da própria produção e do emprego que, por ela (e a partir dela), é gerado.

O mecanismo de ajustamento automático entre oferta e procura nas relações económicas é considerado o pilar da primeira aproximação. Por traz desta noção, regulando o mercado, está a proposta de Adam Smith (1723-1790) que nos remete para a presença (alguns diriam crença) duma "mão invisível", com uma força equiparada à que faz girar a terra, ou à que determina a sucessão das estações do ano. Ganância, competição, individualismo, são condições naturais próprias do homem e por tal, incontornáveis e eternas: nada as poderá alterar (Shaikh, 1978). Com base nesta formulação, a crise não é mais do que uma inevitabilidade, um colateral.

Recorrendo à formulação que Shaikh (1978) utiliza para fixar a visão ortodoxa sobre o sistema capitalista, dir-se-ia que este, deixado entregue a si mesmo, autorreproduz-se eficiente e continuamente, quiçá, eternamente. Assim seria organizado o curso natural da história. Nesta visão não cabe o equacionamento da possibilidade de se estabelecer qualquer tipo de regulação na medida em que o sistema gera, constante e automaticamente, capacidade de autocorreção.

Desmorona-se a infalibilidade desta prerrogativa quando se constata que as crises são frequentes e regulares. Ou seja, o sistema capitalista não anula a ocorrência de episódios de crise, antes pelo contrário, parece certo que, com determinada regularidade, as provoca. $\mathrm{Na}$ 
sua reflexão, Shaikh (1978), convoca alguns factos que sedimentam este argumento. $\bigcirc$ autor credita o trabalho de Clair Mitchell (1874-1948) quando identifica 110 crises entre 1910 e 1920 e o de Paul Samuelson (1915-2009) em que se sinalizam sete recessões nos 30 anos que medeiam 1945 e 1975. Exatamente no plano de corte que separa os dois períodos teve lugar a Grande Depressão, com uma duração de quase 10 anos.

Esta linha de pensamento observa a evidência de que a crise não só não é resolvida pelos mecanismos de autorregulação (do tipo "mão invisível") do sistema capitalista, como, ao que parece, é ela mesma, recorrentemente, um seu output. Inviabilizada a possibilidade de advogar no sentido de que as crises não existem, resta a opção de considerar esses fenômenos externos ao funcionamento "perfeito" do sistema de reprodução capitalista. Este é afetado por crises, é um facto, todavia, por esta leitura, estas em nada têm que ver com o seu funcionamento. Essas anormalidades são justificadas com disrupções próprias da natureza estritamente física (por exemplo, a seca que inviabiliza um ano de colheita), ou da natureza humana. Neste último caso, os exemplos tanto podem dar conta de ciclos psicológicos oscilantes entre otimismo e pessimismo, guerras, revoluções ou idiotices introduzidas por decisões políticas. Qualquer um deles é passível de provocar retração ou expansão da atividade económica (Shaikh, 1978).

Admitindo que o sistema capitalista incorpora flutuações entre Estados de expansão e contração, este fato é encaminhado para a leitura dos ciclos económicos nos quais se dilui, de novo, a ideia de autorregulação como combustível que faz avançar o sistema de um para outro estádio. Nos casos em que a violência do desvio desloca o sistema de produção capitalista para uma crise, a explicação deixa de ser procurada nos fatores internos que o (des)organizam e passam a evocar-se elementos da natureza (física ou humana) que, fruto da sua própria condição, são tidos como forças externas.

A leitura keynesiana surge, pontualmente, no contraponto da tração dominante de tipo laissez-faire. Foi precisamente no rescaldo do colapso mundial denominado Grande Depressão, que as propostas de Keynes se afirmaram. Porventura, o colapso em si mesmo, poderia ser justificado fazendo uso da construção argumentativa apresentada acima. A impossibilidade de aderência à realidade decorre do facto de não se vislumbrar a ação dos mecanismos que reposicionariam, naturalmente, a produção e o emprego nos patamares pré-crise. $\bigcirc$ modelo capitalista de bitola laissez-faire, nesse período, como noutros (como, quiçá, atualmente), apresentava-se incapaz de mobilizar o retorno à normalidade.

É sobre este panorama que medra a proposta keynesiana, de regular o funcionamento do sistema económico, a partir da intervenção dos Estados na mobilização dos investimentos e dos incentivos ao consumo. Contradiz-se a noção de que a oferta determina a sua própria procura e que, deste modo, o capitalismo tende automaticamente para a plena utilização da força de trabalho e dos meios de produção (Shaikh, 1978), com um posicionamento segundo o qual a produção e o emprego, são função do investimento planeado pelos capitalistas. Sob esse prisma, as flutuações no ciclo económico seriam eliminadas se o Estado desempenhasse corretamente as suas funções de regulador do investimento e do consumo.

As crises que pontuam a longa história do capitalismo são também descritas como erros de política (Shaikh, 1978). Esta lógica dualista continua a dominar nas leituras que são propostas à crise atual: é um fenômeno natural que se autocorrigirá, para tal apenas se deve 
proceder no sentido de agilizar os mecanismos do mercado (liberalizar as relações de trabalho, desregular a entrada do mercado em setores de produção de bens de interesse geral); é um problema de incapacidade de liderança política, resolvida esta debilidade será possível retomar a trajetória anterior (resgatar a normalidade, nos padrões de consumo, nos níveis de emprego, no rendimento). Silvey (2010, p. 832) refere-se aos chicago economists dizendo que acompanham o coro de lideres políticos entoando em conjunto um discurso em que se reclamam atuações mais efetivas e inteligentes por parte dos Governos "to keep our model of a capitalist economy from running off the rails" (Silvey, 2010, p. 832).

Entre os dois extremos existem mais pontos de contacto do que à primeira vista se podem identificar. Quer num quer noutro, as expectativas e o que o autor, que temos citado designa por "animal spirits of capitalists" (Shaikh, 1978, p. 3) assumem uma posição central para o sucesso, ou para o falhanço. Em ambas as leituras, a lógica da tendência para o equilibrio é nuclear. Para os defensores do laissez-faire, o mercado encarrega-se de equilibrar as relações entre quem investe, quem produz e quem consome. Para os que perfilham a matriz Keynesiana, o equilibrio resulta da aproximação entre consumidores e produtores (destronando o conflito entre classes).

\section{Considerações finais}

A crise bloqueia o potencial de transformação ou de mudança nas sociedades, nas organizações e nos setores produtivos (Mehta; Xavier, 2012). Num contexto de crise sem precedentes, discutir a força da "mão moderadora" do Estado ou da "mão invisível" do mercado poderá ser insuficiente. Talvez seja mais profícuo equacionar a natureza do poder político e como conceber o posicionamento dos Estados (a natureza dos modelos de desenvolvimentos) face às necessidades de progresso das sociedades. Essa abordagem está há muito no centro das preocupações da geografia crítica (Silvey, 2010).

No início dos anos 1970, autores como Banfield (1973) defendem que as mudanças na mentalidade coletiva, especialmente incidentes nas elites e na classe média, são a causa principal para a crise. Daqui decorre a desvalorização da intervenção do Estado, via planeamento, na resolução das crises? Talvez. Importa considerar os modos que as cambiantes da evolução do sistema capitalista se transpõem para o território (a várias escalas).

Pelo que se discutiu, tomamos como ponto assente que as crises são recorrentes e que a magnitude dos seus efeitos parece aumentar exponencialmente à medida que o processo de crescimento (e concentração) dos centros de decisão se vai intensificando. O ponto crítico surge se se levar em conta o vaticínio de Harvey (2009), para quem, nada mudará enquanto não se abandonar a meta geral dos 3\% de acumulação (crescimento). Para garantir esse rendimento ao investimento, terão de se fazer concessões insuportáveis, quer no plano ambiental, quer no plano social. Dessa pressão, só pode resultar uma sucessão ininterrupta de crises financeiras que serão económicas, sociais e urbanas "it's come to the point when it's no longer a matter of accepting what Margaret Thatcher said, that 'there is no alternative', and we say that there has to be an alternative" (Harvey, 2009, p. 4). 


\section{Referências}

AMIN, S. Capitalism in the Age of Globalization. London: Zed Books, 1997.

ARENDT, H. On revolution. 6. ed. London: Penguin Books, 1963.

BANFIELD, E. A Critical View of the Urban Crisis. The Annals of the American Academy of Political and Social Science, v. 405, n. 1, p. 7-14, 1973.

BOURDIEU, P. Acts of Resistance: Against the Tyranny of the Market. New York: Free Press, 1998.

BRENNER, N.; THEODORE, N. Cities and the Geographies of "Actually Existing Neoliberalism". Antipode, v. 34, n. 3, p. 349-379, 2002.

CARPENTER, S. et al. From Metaphor to Measurement: Resilience of What to What? Ecosystems, v. 4, n. 8, p. 765-781, 2001.

CLARKE, S. Marx's Theory of Crisis. Basingstoke, UK: Palgrave Macmillan, 1993.

DIAMOND, J. Collapse: how societies choose to fail or succeed. New York: Penguin Group, 2005.

FERGUSON, N. Complexity and collapse: Empires on the Edge of Chaos. Foreign Affairs, v. 89, n. 2, p. 18-32, 2010.

FOLEY, D. The Anatomy of Financial and Economic Crisis. Paper prepared to Gildersleeve Lecture, Barnard College, 2009.

FUKUYAMA, F. The end of history and the last man. New York: The Free Press, 1992. . The End of History?. The National Interest, v. 16, p. 3-18, 1989.

GILL, S. Globalisation, Market Civilisation and Disciplinary Neoliberalism. Millennium, n. 24, p. 399-423, 1995.

HABERMAS, J. Legitimation crisis. 2. ed. London: Heinemann Educational Books, 1979.

HARVEY, D. Now find out why you lost your job. Opening speech at the Urban Reform Tent. World Social Forum, Belem, 2009.

HUDSON, R. European integration and new forms of uneven development: but not the end of territorially distinctive capitalisms in Europe. European Urban and Regional Studies, v. 10, n. 1, p. 49-67, 2003.

ISIN, E. Governing Toronto without government: Liberalism and neoliberalism. Studies in Political Economy, n. 56, p. 169-191, 1998.

JESSOP, B; STONE, R. Old City and New Times: Economic and Political Aspects of Deregulation. In: BUDD, L.; WHIMSTER, S. (Ed.). Global Finance and Urban Living: A Study of Metropolitan Change. London/New York: Routledge, 1992. p. 171-192.

KOTZ, D. The Financial and Economic Crisis of 2008: A Systemic Crisis of Neoliberal Capitalism. Review of Radical Political Economics, v. 41, n. 3, p. 305-317, 2009. 
KRUGMAN, P. Acabem com esta crise já. Lisboa: Presença, 2012.

LI, X.; HERSH, J. Understanding capitalism: crisis and passive revolutions. Competition \& Change, v. 6, n. 2, p. 193-212, 2002.

MCKENDREE, A. Synthesizing and Integrating the Crisis Literature: A Reflective Practice.

The Review of Communication, v. 11, n. 3, p. 177-192, 2011.

MEHTA, A.; XAVIER, R. Public Relations Review Tracking the defining moments of crisis process and practice. Public Relations Review, v. 38, n. 3, p. 376-382, 2012.

MORGADO, P.; ROCHA, J. A complexidade em geografia. Lisboa: Centro de Estudos Geográficos/Faculdade de Letras-Universidade de Lisboa, 2006.

PECK, J.; TICKELL A. Searching for a new institutional fix: The after-Fordist Crisis and Global-local Disorder. In: AMIN, A. (Ed.). Post-Fordism: a Reader. Oxford: Blackwell, 1994. p. 280-315.

RIBEIRO, O. Portugal, o Mediterrâneo e o Atlântico. Coimbra: Coimbra, 1945.

SHAIKH, A. An Introduction to the History of Crisis Theories. In: UNION OF RADICAL POLITICAL ECONOMISTS STAFF (Ed.). U.S. Capitalism in Crisis. New York: URPE, 1978. p. 219-241.

SILVEY, R. Development geography: Politics and "the state" under crisis. Progress in Human Geography, v. 34, n. 6, p. 828-834, 2010.

SMITH, A.; RAINNIE, A.; DUNFORD, M. Regional trajectories and uneven development in "the new" Europe: rethinking territorial success and inequality". Working Paper 2-99. Regional Economic Performance, Governance and Cohesion in an Enlarged Europe project sponsored by the Economic and Social Research Council's "One Europe or Several". School of Social Sciences, University of Sussex, 1999.

SUGRUE, T. Introduction. In: SUGRUE, T. The origins of the urban crisis: Race and Inequality in Postwar Detroit. Princeton: Princeton University Press, 2005. p. 1-14.

TABB, W. Marxism, Crisis Theory and the Crisis of the Early 21 st Century. Science $\boldsymbol{E}$ Society, v. 74, n. 3, p. 305-323, 2010. 